\title{
Article \\ Optimization Model for Selective Harvest Planning Performed by Humans and Robots
}

\author{
Ben Harel $^{1, *(\mathbb{D})}$, Yael Edan ${ }^{1}$ (D) and Yael Perlman ${ }^{2}$ (D) \\ 1 Department of Industrial Engineering and Management, Ben-Gurion University of the Negev, \\ Beer-Sheva 8410501, Israel; yael@bgu.ac.il \\ 2 Department of Management, Bar-Ilan University, Ramat Gan 5290002, Israel; yael.perlman@biu.ac.il \\ * Correspondence: benhare@post.bgu.ac.il
}

check for updates

Citation: Harel, B.; Edan, Y.; Perlman, Y. Optimization Model for Selective Harvest Planning Performed by Humans and Robots. Appl. Sci. 2022, 12, 2507. https:// doi.org/10.3390/app12052507

Academic Editor: Panagiotis Tsarouhas

Received: 31 January 2022

Accepted: 25 February 2022

Published: 28 February 2022

Publisher's Note: MDPI stays neutral with regard to jurisdictional claims in published maps and institutional affiliations.

Copyright: (C) 2022 by the authors. Licensee MDPI, Basel, Switzerland. This article is an open access article distributed under the terms and conditions of the Creative Commons Attribution (CC BY) license (https:// creativecommons.org/licenses/by/ $4.0 /)$.

\begin{abstract}
This paper addresses the formulation of an individual fruit harvest decision as a nonlinear programming problem to maximize profit, while considering selective harvesting based on fruit maturity. A model for the operational level decision was developed and includes four features: time window constraints, resource limitations, yield perishability, and uncertainty. The model implementation was demonstrated through numerical studies that compared decisions for different types of worker and analyzed different robotic harvester capabilities for a case study of sweet pepper harvesting. The results show the influence of the maturity classification capabilities of the robot on its output, as well as the improvement in cycle times needed to reach the economic feasibility of a robotic harvester.
\end{abstract}

Keywords: nonlinear programming; agriculture; harvest planning; production

\section{Introduction}

The supply chain for fresh fruit and vegetables involves a number of steps from crop selection to shipment to the customer, including harvesting, processing, packaging, and transporting the produce [1]. Operational research models have been developed for this supply chain at three decision levels: strategic, tactical, and operational [2,3]. The strategic level includes long-term horizon decisions, for example, deciding on farm and plot locations [4]. The tactical level involves medium-term decisions, such as crop selection, scheduling, and allocation [2,5]. The operational level involves short-term decisions, such as water allocation, land preparation, pricing decisions, and harvest scheduling [5-7].

Harvest planning includes several factors (e.g., scheduling and machinery capacity, allocation, and timing) that have been investigated at all three levels. At the strategic level, research has focused on topics such as the number of harvesting machines needed for filling a specific storage capacity [8] and the evaluation of different planting and harvesting alternatives using bio-economics characteristics [2]. At the tactical level, research has focused on allocating harvester machines between a number of fields to reduce costs [9] and on optimizing harvesting and loading sequences to minimize delays in moving products to storage [10]. At the operational level, research has been conducted on optimizing harvest data to maximize mill productivity, and on analyzing the labor effect on fruit quality and quantity at harvest $[2,11,12]$. However, there are no studies examining operational decisions related to the harvesting of individual fruit.

Selective harvesting of high-value crops, such as apples, tomatoes, and broccoli, is currently performed mainly by humans, rendering it one of the most labor-intensive and expensive agricultural tasks [13]. Any attempts to mechanize all or parts of the supply chain for these crops must take into account the decades-long research on the robotization of many different agricultural applications, such as transplanting, spraying, cultivating, trimming, and selective harvesting [14]. This research has indeed indicated the technical feasibility of using robotic harvesters in orchards (e.g., apples $[15,16]$ and citrus $[17,18])$, 
greenhouses (e.g., tomatoes [19] and sweet peppers [20]) and open fields (e.g., melons [21] and asparagus [22]), but the robots developed to date still lack commercial applicability, since they have failed to reach the efficiency of human harvesters [13,23].

A robotic harvester must detect the fruit, reach the fruit, decide whether to harvest the fruit, and then grasp and disconnect the fruit from the branch. The harvest decision of a selective robotic harvester thus includes a number of aspects. First, methods for maturity classification must be developed [24,25]. Second, since many fruits are hidden or partially obscured, the best camera viewpoints for maturity classification must be selected [26]. Since additional viewpoints cost time, an intelligent decision as to the necessity for an additional viewpoint and its location is needed [27]. The third and last aspect investigates the operational considerations of maturity classification and harvesting, namely, deciding whether the fruit is ripe and whether to harvest it, based on a consideration of the above points. By addressing these aspects, the harvest decision of a selective robotic harvester can be improved.

To the best of our knowledge, no research has examined the decision making of a selective robotic harvester. This research lacuna may be attributed to the research focus on proving the technical feasibility of robotic harvesters [23], i.e., developing sensing and grasping capabilities. Once the technical feasibility of robotic harvesters has been proven, successful implementation and commercialization will depend on their integration into the production cycle [28], similarly to milking robots: after the technical feasibility of the milking robot had been successfully demonstrated, different operational research aspects were investigated at various levels, including optimal allocation in a robotic milking barn [29], the design and layout of an optimal barn [30], and prediction of the milking robot utilization [29].

One of the operational aspects of a harvesting robot is harvest planning, which includes scheduling, routing, and resource allocation to ensure high quality of the final products [1]. The agricultural environment is characterized by several variabilities and challenges, deriving from its unstructured and dynamic make-up and the biological nature of the product $[27,31,32]$. Fruit and vegetable crops vary widely in physiology and management practices, which may involve multiple harvests in a single season [33]. In particular, in high-value crops, harvesting is performed several times along a production season. These crops are generally non-staple crops, such as fruit, vegetables, ornamentals, and spices [34]. For such crops, the decision to harvest a specific fruit/vegetable depends on the fruit/vegetable maturity level, the harvesting capacity, and market demand.

In this work, we aimed to develop a model for selective harvesting based on the maturity of the fruit, where harvesting can be performed by human workers or robots, with each type of harvester having different abilities to identify maturity. The model formulation and analyses are demonstrated in numerical studies using sweet pepper harvesting as a case study.

We determined the optimal harvest production order to maximize farmers' profit. The production order defines how many peppers of each maturity level to harvest on each specific harvest day along the harvesting season. The production order defines the harvesting capacity needed, i.e., the number of workers/robots required to achieve this production. Usually, different types of workers are available for harvesting, and in the future, robotic harvesters might also be integrated into the harvesting process $[14,23]$. The factors that determine the type of worker include costs (salary), the number of peppers each worker can harvest each day, and the worker's ability to classify the peppers into different maturity classes. For example, an inexperienced worker is able to classify peppers into only two maturity classes-mature and immature. An experienced worker can classify the pepper into four maturity classes-immature, partly mature, mostly mature, and must be harvested [35]. Therefore, more experienced workers, who are better able to estimate the pepper maturity level, will harvest the fruit at the best fit time, resulting in an overall higher pepper weight (since the fruit will stay longer on the plant and continue to develop). 
A robotic harvester will be able to non-destructively classify the exact maturity level [24,36-39] and will have a higher harvest capacity than a human worker, but will also have higher costs [23]. Only a few previous studies have investigated and analyzed the economic effect of robotic harvesting, focusing on the machine cost per area unit, compared to human workers $[1,40]$. This work extends the literature by estimating the selective robotic harvester quality savings, taking into consideration both the cost (comparing robot costs to manual costs) and the effect of maturity classification using a robotic harvester (the quality effect).

The remainder of this paper is organized as follows: Section 2 gives the relevant background and previous research. Section 3 describes in detail the basic formulation of the harvesting problem, and Sections 4 and 5, respectively, present expansions of the basic formulation and numerical studies. Finally, Section 6 concludes the paper.

\section{Literature Review}

Harvest yields tend to be uncertain regarding quantity, quality, and timing, due to dynamic and unpredictable weather, soil, and water conditions [1,41]. Moreover, the harvesting time of individual fruits or vegetables will influence the production yield and quality [11]. The harvest time is affected by many factors, such as cultivation practices, weather conditions, soil conditions, geographical location, rate of quality decay, storage capacity, the required processing needed, and transport considerations [1,11,41]. Given the yield and quality attributes and the transport and storage restrictions, mathematical optimization techniques, such as linear or integer programming, are often used to determine the best possible harvest time [8]. This type of programming determines the best harvesting time for different objective functions, such as maximum profit or minimum expenses $[2,11]$. To date, this best harvesting time has been considered at the field level only for non-selective harvesting (i.e., when to harvest a specific field with a single harvest).

Another decision that must be made before harvesting concerns the number of workers to recruit for the harvest season. Labor costs are a significant expense in agricultural production, specifically in the harvesting process [42]. Harvesting often involves migrant seasonal workers and requires recruitment processes that take time and require planning [43]. Furthermore, it is necessary to maintain a balance between ensuring a sufficient number of workers to harvest the ripe products (not missing harvestable produce due to a lack of workers) and ensuring that workers are fully utilized to reduce operational costs.

Usually, the harvest planning problem is modeled using a mathematical formulation and then solved by different operational research methods [2]. Integer linear programming, the most common method [2], has been used to find the optimal date for grape and apple harvesting, taking into consideration operational costs and fruit quality [44,45]. In these studies, the harvest date was set for non-selective harvesting, i.e., harvesting the whole field at once. A different planning model for wine grape harvesting involving uncertainty combined integer linear programming and robust stochastic optimization [26]. Other studies have used dynamic programming [10] and simulation models [46] to solve problems in harvest planning. However, all of these studies addressed decisions related to the whole field and did not relate to individual fruits.

Any study related to the modeling of harvest planning must take the following features into consideration, as reviewed in [1]:

- Time window constraints-The model should consider the optimal time for harvesting and the quality decay resulting from harvesting outside of that time window, as well as its effect on revenues.

- Resource limitations-These include capacity and productivity constraints, together with labor and machine availability.

- Yield perishability-The deterioration of fresh products during the post-harvest period must be taken into account. Yield perishability can be modeled in several ways, including continuous deterioration curves, a loss factor for each period after harvesting, and the effect of product deterioration on customer demand. 
- Uncertainty-There is uncertainty in the harvest yield (quantity and quality), due to unknown weather conditions and the inherent variability of agricultural processes.

- Inventory control-The inventory should be considered in terms of holding costs, duration of keeping in the inventory constraints, or as a decision variable.

Integrating all of the above elements into a single model is complicated and may be impossible to solve in reasonable computational times. Therefore, heuristics algorithms are usually developed to derive an operational solution [47].

None of the studies covered in the review [1] included all the aforementioned features, and only two included four out of the five features. Maatman et al. created a multiperiod stochastic model to determine the cultivating strategy for crops under rainfall uncertainty [48]. This model did not include time window constraints, i.e., the optimal time for harvesting was not considered. Annetts and Audsley considered four out of the five features described above. Their study dealt with cultivating strategy and machinery selection [49], aiming to maximize profits while minimizing environmental impact. The developed model did not include the uncertainty feature; the researchers used historical weather data to determine the available working hours of the machines but did not consider the weather data effect on crop maturity, yield, and costs [49]. In addition, none of the above models considered selective harvesting (focusing on decisions related to individual fruit). The current paper addresses this knowledge gap by focusing on decisions related to individual fruit and taking into consideration four features for selective harvesting. The inventory control feature was excluded, because we assume that fresh fruit are supplied on the same day of harvest.

The literature review revealed three studies that solved a problem with similarities to planning the harvest of a selective crop. Arnaout and Maatouk developed a model for scheduling the harvest operation of grapes to maximize harvest quality with minimum cost. Their model used a quality decay function to measure the quality loss of the grapes and its effect on the profits corresponding to the harvest date [47]. However, in this case, the grape crop was harvested once in a season (not selectively harvested). In contrast, crops such as sweet peppers require selective harvesting, once every few days. Each fruit could be harvested at different maturity levels over an extended period. Therefore, when planning to address the harvest of a selective crop problem, the inventory level and product quality can be controlled via the right decision related to the harvested product's maturity level.

Golenko-Ginzburg et al. developed a multilevel decision-making system for human and machine cotton harvesters. They created a hierarchical system of three levels; the first level determines the harvesting speed, the second level re-allocates the resources to create balanced teams, and the third level re-allocates the teams among farms, aiming to maximize the probability of completing cotton harvesting by a due date [50]. The principle of integrating two types of resources (man-machine) is similar to the current work formulation. However, cotton, similar to grapes, is a non-selective crop and is harvested all at once. Therefore, adjustment for a selective crop, such as sweet peppers, was needed and was the aim of this paper.

Albornoz et al., suggested an approach for grape-selective harvest scheduling and planning via management zone delineation [51]. Their work minimized the total costs of harvest operations and established planning and scheduling for selective harvest of each selected management zone. Although dealing with selective harvesting, their article did not consider the fruit growth function or the maturity status of individual fruit.

In this paper, we present $a$ model for deciding on the selective harvest of an individual fruit. Four features are considered in the model, which is based on an economic analysis that takes into account robot/worker capabilities and the growth model of the fruit. The model is demonstrated for sweet pepper harvesting, but it is general and can be applied to other crops requiring selective harvesting. 


\section{Problem Description and Formulation}

\subsection{Growth Function}

Sweet pepper fresh weight, similar to other fruits, is determined in terms of days after anthesis (DAA). Anthesis is taken as time zero, after which the pepper continues to grow, and after $d_{m}$ days from anthesis, if not harvested, the pepper is considered rotten and cannot be supplied to the customer. Let $W(d)$ denote the weight of a pepper $d$ days after anthesis. $W(d)$ is determined via the pepper growth function. Several growth functions for sweet peppers can be found in the literature [52], and the following common growth function was used [52]:

$$
W(d)=\frac{W_{\max }}{\left(1+e^{-a\left(d-d_{m}\right)}\right)}
$$

where $W_{\text {max }}$ is the maximum weight of the pepper, $d_{m}$ is the maximal value of $d$, and $a$ is a constant determining the curvature of the growth pattern [33].

The pepper maturity class is determined by $d$. In the future, a robotic harvester might be able to identify the exact $d$ for the pepper. However, workers can distinguish only between pepper maturity classes (they cannot identify the exact $d$ of a pepper), since it would require tagging each flower, which is an expensive and complicated task. Therefore, the maturity classes are modeled as follows; the lowest maturity class is defined as pepper DAA between $\left[d_{1 \text { start }}, \ldots, d_{1 \text { end }}\right]$, the second-lowest maturity level is defined as pepper DAA between $\left[d_{2 s t a r t}, \ldots, d_{2 e n d}\right]$, etc.

\subsection{Model Formulation}

\section{Inputs}

$n$-number of periods

$m$-number of maturity levels

$d$-number of days after anthesis

$d_{\text {jstart }}-$ min days after anthesis of maturity level $j$

$d_{\text {jend }}$-max days after anthesis of maturity level $j$

$y_{d, 1}$-number of peppers $d D A A$ available to harvest in the first period

$I_{0}$-number of peppers at anthesis each day

$C_{h}$-harvester capablities in one period

$p$-price per kilogram of pepper fresh weight

$W(d)$-fresh weight (kilogram) of pepper $d$ days after anthesis

$S$-harvester's salary/rental cost through all planning horizons

F-total fixed expenses through all of planning horizons, including utilities, land, water, fertilization, planting, and taxes

\section{Variables}

$N$-number of harvesters (hired workers or equivalent numbers of robots see Section 5.2.2) (decision variable)

$H_{j, t}$-peppers harvested from maturity class $j$ in period $t$ (decision variable)

$\mathrm{THW}_{t}$-total harvest weight of the peppers in period $t$ (fresh weight in kilograms)

$A_{j, t}$-peppers from class $j$ available to harvest at the beginning of period $t$

$P_{d, t}$-peppers $d$ days after anthesis that are harvested in period $t$

$Y_{d, t}$-peppers available to harvest $d$ days after anthesis at the beginning of period $t$

The farmer has two decisions to make: the number of harvesters to use for the harvest season $(N)$, and the number of peppers to harvest from each maturity class at each period $\left(H_{j, t}\right)$. Since we are dealing with selective harvesting, the number of harvesters is calculated as the number of workers or the equivalent-performing robotic harvesters (see Section 5.2). The harvest season is $n$ periods long, and the harvesters can distinguish between peppers in $m$ maturity classes. 
The objective function represents the profit to the farmer and includes the following components: income from the harvested peppers (calculated as the fresh weight of the harvested peppers $\left(T H W_{t}\right)$ multiplied by the price per kilogram $(p)$ ); variable expenses (calculated as the number of harvesters $(N)$ multiplied by the workers' salaries or the robots' rental cost $(S)$ through all planning horizons); the total fixed expenses $(F)$ through all planning horizons (calculated by summing expenses due to utilities, land, water etc.):

$$
\operatorname{Max} Z=p \times \sum_{t=1}^{n} T H W_{t}-N \times S-F
$$

subject to: (the constraints are explained one by one below):

$$
\begin{gathered}
Y_{1, t}=I_{0} \quad \forall t=2 \ldots n \\
Y_{d, t}=Y_{d-1, t-1}-P_{d-1, t-1} \quad \forall t=2 \ldots n, d=2 \ldots d_{m} \\
Y_{d, t} \geq P_{d, t} \quad \forall t=1 \ldots n, d=1 \ldots d_{m} \\
H_{j, t}=\sum_{d=\text { djstart }}^{\text {djend }} P_{d, t} \forall t=1 \ldots n, j=1 \ldots m \\
A_{j, t}=\sum_{d=d j s t a r t}^{\text {djend }} Y_{d, t} \forall t=1 \ldots n, j=1 \ldots m \\
A_{j, t} \geq H_{j, t} \forall t=1 \ldots n, j=1 \ldots m \\
\sum_{j=1}^{m} H_{j, t} \leq N \cdot C_{h} \forall t=1 \ldots n \\
T H W_{t}=\sum_{d=1}^{d m}\left(W(d) \times P_{d, t}\right) \forall t=1 \ldots n
\end{gathered}
$$

Equations (3)-(5) define the mechanism of pepper growth in the greenhouse using the variables $Y_{d, t}$ and $P_{d, t}$. The number of available peppers $d$ DAA at the beginning of the planning horizon $\left(Y_{d, 1}\right)$ is given. Since the actual $d$ of a pepper is unknown to the workers, the decision is made based on the maturity classes $\left(A_{j, t}\right.$ and $\left.H_{j, t}\right)$, as described above. The composition of each maturity class is obtained from Equations (6) and (7). In addition, the number of peppers harvested from each maturity class is limited by the peppers available, seen in Equation (8), and the maximal number of peppers harvested is determined by the number of harvesters in Equation (9). The actual harvest weight (THW) is determined via the harvested pepper's d, as in Equation (10).

If we take into consideration the potential of a robotic harvester, the above set of constraints is somewhat different. If we assume that the robots can identify the exact DAA $d$, then $H_{j, t}=P_{d, t}$ and thus constraints 6-8 can be removed and $P_{d, t}$ is replaced by $H_{j, t}$ in the remaining set of constraints.

This model formulation contains $[(n \times m)+1]$ variables and $[n \times(m+1)+2]$ constraints. We note that different methods for solving nonlinear programming differ in the computational effort expressed by the number of variables and constraints.

\subsection{Dealing with Uncertainty}

The complex aspect of this formulation is to update the value of $P_{d, t}$, which determines the harvested yield weight and the relation between $H_{j, t}$ and $P_{d, t}$. To update the values of $Y_{d, t}$ between periods, the value of $P_{d, t}$ must be known, as is shown in Equation (4). 
To determine the exact value of $P_{d, t}$, the distribution of the harvested peppers $\left(H_{j, t}\right)$ within the different DAAs must be known. Since it is impossible to know the actual DAA of a harvested pepper, a stochastic process must be considered. We considered four ways to deal with this problem:

- $\quad$ Distribute the harvested peppers uniformly among the different DAAs.

- Distribute the harvested peppers in proportion to the available peppers of each DAA.

- $\quad$ Create a worst-case scenario in which the peppers with the lowest weight (lower DAA) available in a maturity class will be harvested.

- Create a best-case scenario in which the peppers with the highest weight (highest DAA) available in a maturity class will be harvested.

For example, in a problem in which the second maturity level is defined as peppers of 5 to 7 DAAs, let us assume that in period 1, the peppers available are: $Y_{5,1}=4$, $Y_{6,1}=6, Y_{7,1}=2$. This implies that $A_{2,1}=\sum_{k=5}^{7} Y_{k, t}=4+6+2=12$. Now, let us assume the algorithm decided to harvest six peppers from level 2 in period $1: H_{2,1}=6$.

- $\quad$ The first method, distributing uniformly, will set $P_{5,1}=2, Y P_{6,1}=2, P_{7,1}=2$.

- The second method, distributing in proportion, will set $P_{5,1}=\frac{4}{12} \times 6=2$, $P_{6,1}=\frac{6}{12} \times 6=3, P_{7,1}=\frac{2}{12} \times 6=1$.

- $\quad$ The third method, the worst-case scenario, will set $P_{5,1}=4, Y P_{6,1}=2, P_{7,1}=0$.

- The fourth method, the best-case scenario, will set $P_{5,1}=0, Y P_{6,1}=4, P_{7,1}=2$.

All four ways suggested for dealing with uncertainty are a function of the decision variables and, therefore, create a nonlinear formulation.

\section{Model Extensions}

The suggested formulation (Section 3) is based on certain assumptions that enable a solution to be reached in reasonable computational time. This section discusses and offers modifications of the formulation to accommodate different aspects of harvest planning.

\subsection{Limiting the Harvested Rows and Deciding on the Rows to Harvest}

In the current formulation, all fruits in the greenhouse are available for harvesting in each period. The greenhouse is separated into rows. Usually, the harvesters harvest only a subset of the total rows in the greenhouse (block) each working day, spacing the time between one harvest cycle and the next. Such spacing enables fruits to continue to grow (increase weight) and creates a higher supply of grown peppers to harvest in the next harvest cycle of the block (the subset). Moreover, harvesting only a subset of rows saves transition times while advancing along the rows, creating a more productive environment.

An additional index, the block index, should be added to the formulation to apply this approach. However, such a change will increase the number of variables and constraints in the current formulation, making it difficult to solve in a reasonable computational time. Therefore, we applied an additional solution for this approach, which is easier to solve; we ran the formulation for each block of rows separately. By doing this, the definition of time between periods could be changed. Instead of representing one day, the time between periods could be the time between two harvest cycles of the same block. This change in the definition of time between periods requires scaling the growth function to the appropriate time, rather than days. For example, if each block is harvested every ten days, the growth function should be scaled from the change in fruit weight $d$ DAA to change in fruit weight $10 \times d$ DAA.

\subsection{Modeling the Change in Pepper Price}

The price of a kilogram of fresh peppers varies between different periods along the harvesting season. While this price variation affects the decision of how many peppers are to be harvested in each period, the price for each period cannot be known in advance, since it relies on market supply and demand. Therefore, the price can only be estimated using post data. Once the prices are estimated, they can be added to the formulation as input. 
Then, instead of multiplying the total harvest weight (THW) of all planning horizons for the same fixed price per kilogram $(p)$, the THW of each period can be multiplied by the specific period.

\section{Numerical Studies-Harvesters with Different Capabilities to Classify Pepper Maturity Levels}

As described in the Introduction, workers may have different capabilities to classify peppers into different maturity classes. A robotic harvester may be able to identify the exact maturity level of a pepper, but renting a robot incurs a certain cost. Based on the different harvesting capabilities, farmers need to select harvesters. Three numerical studies were conducted representing problems faced by a typical farmer. The first (Section 5.1) explores different types of worker. The second (Section 5.2) analyzes the potential capabilities of a robotic harvester in comparison to human harvesters. Finally, an economic return-oninvestment analysis for the robotic harvester was conducted (Section 5.3) based on the results of the second example. The model parameters were chosen based on $[20,53,54]$ and data obtained from an interview with a sweet pepper farmer in Israel for a sweet pepper greenhouse of a size of 1.2 hectares (Table 1). Since the aim of the numerical studies was to demonstrate the practical implementation of the model, small/medium-size problems were analyzed, where the number of periods $n$ was set to 20 . The problems were solved via a Microsoft Excel solver add-in using the generalized reduced gradient nonlinear method, which derives a local optimum solution (solver's maximal size is 200 decision variables and 100 constraints).

Table 1. Model parameters for the numerical example analysis.

\begin{tabular}{cccccccc}
\hline \multicolumn{2}{c}{ General } & \multicolumn{2}{c}{ Workers } & \multicolumn{2}{c}{ Yield } & \multicolumn{2}{c}{ Growth Function } \\
\hline$n$ & 20 & $S$ & 3530 & $y_{d, 1}$ & $7000 \forall d$ & $d_{m}$ & 30 \\
\hline$p$ & 2 & $C_{h}$ & 6750 & $I_{n 0}$ & 7000 & $W_{\max }$ & 250 \\
\hline & & & & & & $a$ & 0.3 \\
\hline
\end{tabular}

\subsection{Analysis of the Type of Worker}

This numerical example aims to analyze the effect on the objective function of the workers' ability to classify peppers into multiple classes. The workers were classified into three types based on their experience, where the assumption was that more experienced workers can classify fruit into a higher number of maturity levels. The data regarding the classifying ability of each worker is given in Table 2. Two versions of the model formulation were run for each worker type. The first version ran the exact formulation described in Section 3.2 to determine the optimal number of workers and how many peppers to harvest from each maturity class (Section 5.1.1). In the second version, the number of workers was fixed, and the only decision variable was the number of peppers harvested from each maturity class for a given number of workers (Section 5.1.2).

Table 2. Data for the ability of three types of worker to classify peppers into maturity levels $(m)$.

\begin{tabular}{cccccccccc}
\hline & Type A: $\boldsymbol{m = 2}$ & \multicolumn{3}{c}{ Type B: $\boldsymbol{m}=\mathbf{3}$} & \multicolumn{3}{c}{ Type C: $\boldsymbol{m = 4}$} \\
\hline Class & $\boldsymbol{d}$ Start & $\boldsymbol{d}$ End & Class & $\boldsymbol{d}$ Start & $\boldsymbol{d}$ End & Class & $\boldsymbol{d}$ Start & $\boldsymbol{d}$ End \\
\hline 1 & 31 & 45 & 1 & 31 & 40 & 1 & 31 & 40 \\
\hline 2 & 46 & 60 & 2 & 41 & 50 & 2 & 41 & 45 \\
\hline & & 3 & 51 & 60 & 3 & 46 & 50 \\
\hline
\end{tabular}




\subsubsection{Number of Workers Is a Decision Variable}

The results in Table 3 show that the best performance for a variable number of workers was derived for the experienced workers (Type C). However, the mid-experienced workers (Type B) obtained a higher total harvest weight with only a slight difference $(0.4 \%$ less) in the profit. It seems from the results that for each type of worker a solution with a different number of workers was derived. A possible reason for this result is that the generalized reduced gradient method produces a local optimum solution. The difference between the profit values signifies the maximal difference in workers' salaries that the farmer will agree to pay for the change in the type of worker. The difference resulted in $14.2 \%, 0.4 \%$, and $13.5 \%$ improvements in profit when changing the workers from Type $\mathrm{C}$ to $\mathrm{A}$, Type $\mathrm{C}$ to $\mathrm{B}$, and Type B to A, respectively. The formulation results lead to two strategies for the harvest plan (Figure 1) based on the inputs in Table 1.

Table 3. Results of the numerical example for the analysis of worker performance.

\begin{tabular}{lcccccc}
\hline & \multicolumn{3}{c}{ Variable Number of Workers } & \multicolumn{3}{c}{ Fixed Number of Workers } \\
\cline { 2 - 7 } & N & Profit & THW & $N$ & Profit & THW \\
\hline Type A: $m=2$ & 2 & $98,066.7$ & $52,553.37$ & 2 & $98,066.7$ & $52,553.37$ \\
\hline Type B: $m=3$ & 4 & 111,593 & $62,836.68$ & 2 & 107,918 & $57,478.77$ \\
\hline Type C: $m=4$ & 3 & 112,049 & $61,304.32$ & 2 & 108,022 & $57,531.19$ \\
\hline$m=$ \# maturity classes. & & & & &
\end{tabular}

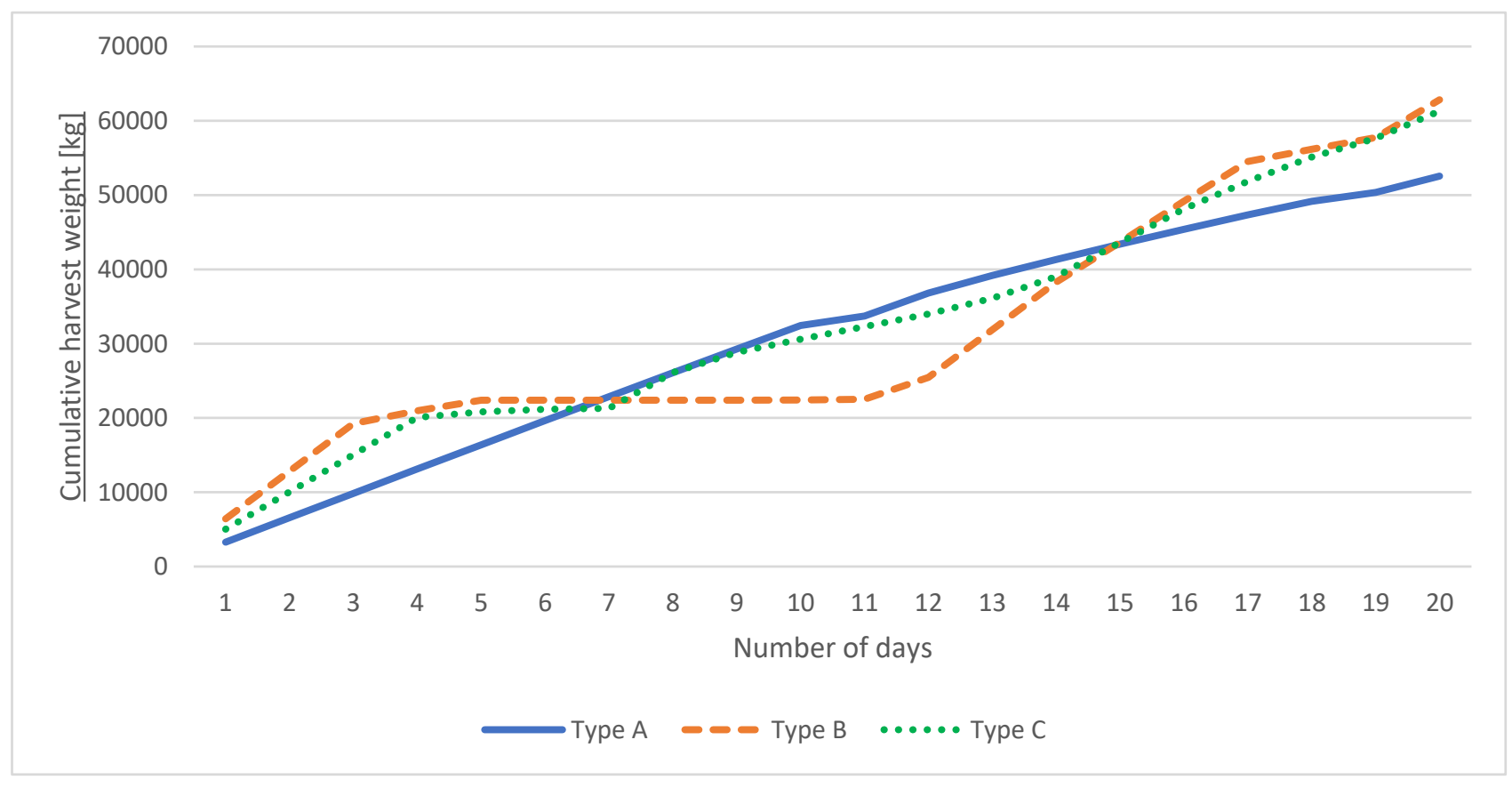

Figure 1. The cumulative total harvest weight (kilogram) for each worker type.

In the first strategy, workers of Types $A$ and $C$ harvest peppers at the same rate throughout the whole month. In the second strategy, workers of Type B harvest only at the beginning and at the end of the month. This strategy allows the fruit to keep gaining weight until the harvest at the end of the month.

The first strategy is simpler to implement, since the solution fully utilizes the workers/robots. The second strategy has the potential for better utilization, but requires tight planning. Since there are periods without harvesting, in those periods, the workers/robots can work in a different greenhouse (or different areas in a larger greenhouse) by synchronizing the harvest periods. 


\subsubsection{Fixed Number of Workers}

This example demonstrates how workers' experience affects the total harvest weight. The formulation was executed for the three sub-cases with a fixed number of workers as input (the number of workers, $N$, was set to two instead of being a decision variable). The results in Table 3 show that there is a slight difference between the performances of Type $\mathrm{B}$ and Type $\mathrm{C}$ workers. However, there are more marked differences in the total harvest weight between Type A and Types B and C, with $9.3 \%$ and $9.5 \%$ improvements, respectively.

\subsection{Analysis of the Robotic Harvester Capability}

The assumption is that a robotic harvester can potentially classify fruits into multiple maturity classes, even to their exact DAA, by using AI methods [52]. Peppers are therefore harvested at the optimal time giving higher weights. In this numerical example, we compared different types of human harvesters (Table 1) with a robotic harvester.

5.2.1. Difference in the Total Harvest Weight between Robotic and Human Harvesters with the Same Capabilities

This analysis investigated the difference in the total harvest weight (THW) between a single robot and a number of workers of different types, where the robot and the total number workers had the same harvest capabilities $C_{h}$. This type of analysis can be applied to estimate the cost efficiency of a robotic harvester and the maximal price a farmer will agree to pay for such a robot for one month of operation. To evaluate how the robot's ability to classify peppers according to their DAA affects the harvest weight (THW) in one month, the THW of a robot was compared to the THW of a number of workers, where the number of workers was set to a number giving the same $C_{h}$ as one robot (Table 1). The robot's THW was then compared to the THW of the workers for each worker type. Six workers $(N=6)$ were selected as the basis for comparison, with a total capacity of $C_{h}=40,500$ fruits per working day being equivalent to the ability of one robot. Any number lower than this (produced by six workers) creates an imbalanced use case with a high supply of peppers in the greenhouse, resulting in the harvesting of peppers solely from the highest maturity class. Similarly, any number higher than $C_{h}=40,500$ creates a use case in which all the peppers available in the greenhouse are harvested.

The results in Table 4 show the robotic harvester's high potential, with a 12.28, 7.33, and $4.9 \%$ increase in the THW when compared to workers of Types A, B, and C, respectively. The results show the importance of the ability to classify maturity for evaluating the feasibility of using a robotic harvester. Since the results are presented in terms of harvest weight, the higher the pepper price, the greater the advantage of the robot when compared to the workers. From Table 4, the difference in THW between the robot and the workers can be calculated as quality savings [55] (pp. 683-687) measured for the planning horizon period. For example, the quality savings between the robot and Type B workers is $2716 \mathrm{~kg} / \mathrm{month}$, resulting in overall savings of $23,765 \mathrm{~kg} /$ year. The quality savings can then be used to calculate return-on-investment measures. This analysis also reveals the importance of decreasing the robot's cost to increase its economic feasibility, as expected.

Table 4. The total harvest weight (kilogram) for a harvester robot and for different types of workers with the same $C_{h}$ for one month and for an estimated growing period of 35 weeks.

\begin{tabular}{ccccc}
\hline Harvester Type & Robot & 6 Type A Workers & 6 Type B Workers & 6 Type C Workers \\
\hline $\begin{array}{c}\text { THW }(\mathrm{kg}) \\
\text { in one month }\end{array}$ & $37,069.03$ & $32,885.64$ & $34,352.45$ & $35,253.99$ \\
\hline $\begin{array}{c}\text { THW }(\mathrm{kg}) \\
\text { in one year } \\
(35 \text { harvest weeks })\end{array}$ & 324,354 & $287,749.35$ & $300,583.93$ & $308,472.41$ \\
\hline
\end{tabular}




\subsubsection{Required Cycle Time for the Harvester Robot}

This analysis aimed to assess the required cycle time for the harvester robot to reach the same THW of the human harvesters based on the results of the analysis in 5.2.1 (Table 4). The required robot harvest capabilities $\left(C_{h}\right)$ to achieve the same THW were searched manually using the "goal seek" method. The results show that robot harvest capabilities $\left(C_{h}\right)$ of $34,000,36,070$, and $37,370 \mathrm{~kg}$ in one working day are needed to reach the same THW as Type A, B, and C workers, respectively. However, it should be remembered that the robot's capabilities were compared to the capabilities of six workers. Therefore, assuming that the robot can work $20 \mathrm{~h}$ a day [56], Table 5 shows the equivalent number of workers for different harvester robot cycle times. It has been reported that harvester robots achieved cycle times between 5.5 and $24 \mathrm{~s}$ to harvest a single fruit [20], which according to this analysis, is equal to 0.5 to 2.3 workers (Table 5). The results show the importance of the robot harvest capabilities in one period and the improvement in cycle times needed for a robotic harvester to reach economic feasibility.

Table 5. The equivalent number of workers for different harvester robot cycle times.

\begin{tabular}{cccc}
\hline Robot Cycle Time & Type A Workers & Type B Workers & Type C Workers \\
\hline 0.5 & 25.4 & 24.0 & 23.1 \\
\hline 1 & 12.7 & 12.0 & 11.6 \\
\hline 2.5 & 5.1 & 4.8 & 4.6 \\
\hline 5.5 & 2.3 & 2.2 & 2.1 \\
\hline 7.5 & 1.7 & 1.6 & 1.5 \\
\hline 10 & 1.3 & 1.2 & 1.2 \\
\hline 12.5 & 1.0 & 1.0 & 0.9 \\
\hline 15 & 0.8 & 0.8 & 0.8 \\
\hline 20 & 0.6 & 0.6 & 0.6 \\
\hline 25 & 0.5 & 0.5 & 0.5 \\
\hline
\end{tabular}

\subsection{Payback Period and Rate-of-Return Analysis}

Two return-on-investment measures for the harvester robot were calculated, similar to the analysis suggested by [55] (pp. 683-687): the payback period and the internal rate of return (IRR) in five years. The payback period is the number of years required for incoming cash flows to balance cash outflows. The IRR is the annual growth rate that an investment is expected to generate [55]. The analysis required cost estimation of the investment in the robot and the savings via its use. It includes the following data based on SWEEPER project estimations [56]:

- The cost of the robot is set at $100,000,130,000$, or $160,000 €$

- The harvest season lasts 35 weeks per year

- Manual harvesting requires $3 \mathrm{~s} /$ pepper

- Robot harvesting requires $10 \mathrm{~s} /$ pepper

- Manual harvesters work five months, five days/week, $8 \mathrm{~h} /$ day

- A robotic harvester works $20 \mathrm{~h} /$ day, six days/week

- Manual harvest hourly rates of 16.5 (corresponding to rates in the Netherlands) and $9.97 €$ (corresponding to rates in Israel) result in 23,100 and $14,000 € /$ year, respectively

In addition, the analysis estimates robot operation costs of $20,000 €$ for the first two years and $10,000 €$ for the years thereafter. The use tax rate and the depreciation were based on the United States Internal Revenue Service's Modified Accelerated Cost Recovery System (MACRS), as in ref. [55] (p. 684).

The analysis included the following data, based on the corresponding use case (Section 5.2.1); the use case considers four harvest weeks of planning, multiplied by 8.75 
to represent the number of plannings per year. The formulation result was used to estimate the robot quality savings. Type B workers were chosen for the analysis, resulting in $23,769.4 \mathrm{~kg} /$ year of quality savings.

The results in Table 6 show that, considering the highest robot cost $(160,000 €)$, for pepper prices lower than 1.25 and $1.75 € / \mathrm{kg}$, it will take more than five years to recover the robot investment in both the Netherlands and Israel. The $p$ of sweet peppers in the Netherlands varies between $1.2-1.3 € / \mathrm{kg}$, resulting in 4.72 payback periods and $1.9 \%$ IRR. The $p$ of sweet peppers in Israel varies between $1.7-2.2 € / \mathrm{kg}$, resulting in 3.98 payback periods and $7.8 \%$ IRR.

Table 6. Payback periods (years) and IRR in five years in the Netherlands and Israel for different pepper $p$ and robot costs.

\begin{tabular}{|c|c|c|c|c|c|c|c|c|c|c|c|c|}
\hline \multirow[b]{3}{*}{$\begin{array}{c}\text { Pepper } p(€) / \\
\text { Robot Cost }(€)\end{array}$} & \multicolumn{6}{|c|}{ The Netherlands } & \multicolumn{6}{|c|}{ Israel } \\
\hline & \multicolumn{3}{|c|}{ Payback Periods } & \multicolumn{3}{|c|}{ IRR in Five Years (\%) } & \multicolumn{3}{|c|}{ Payback Periods } & \multicolumn{3}{|c|}{ IRR in Five Years (\%) } \\
\hline & $100 \mathrm{~K}$ & $130 \mathrm{~K}$ & $160 \mathrm{~K}$ & $100 \mathrm{~K}$ & $130 \mathrm{~K}$ & $160 \mathrm{~K}$ & $100 \mathrm{~K}$ & $130 \mathrm{~K}$ & $160 \mathrm{~K}$ & $100 \mathrm{~K}$ & $130 \mathrm{~K}$ & $160 \mathrm{~K}$ \\
\hline 1 & 3.72 & 4.58 & 5.50 & 10.5 & 2.9 & 0.0 & 4.89 & $>6$ & $>6$ & 0.0 & 0.0 & 0.0 \\
\hline 1.25 & 3.21 & 3.99 & 4.72 & 16.2 & 7.8 & 1.9 & 4.05 & 5.00 & $>6$ & 7.3 & 0.0 & 0.0 \\
\hline 1.5 & 2.89 & 3.52 & 4.19 & 21.1 & 12.4 & 5.9 & 3.46 & 4.29 & 5.08 & 13.3 & 5.2 & 0.0 \\
\hline 1.75 & 2.63 & 3.17 & 3.76 & 25.7 & 16.6 & 9.8 & 3.05 & 3.76 & 4.46 & 18.5 & 9.9 & 3.8 \\
\hline 2 & 2.42 & 2.91 & 3.40 & 30.3 & 20.3 & 13.6 & 2.76 & 3.33 & 3.98 & 23.3 & 14.5 & 7.8 \\
\hline 2.25 & 2.24 & 2.70 & 3.14 & 34.7 & 24.0 & 16.8 & 2.53 & 3.04 & 3.58 & 27.9 & 18.3 & 11.6 \\
\hline 2.5 & 2.08 & 2.52 & 2.93 & 39.0 & 27.6 & 19.8 & 2.33 & 2.81 & 3.27 & 32.4 & 22.1 & 15.1 \\
\hline 2.75 & 1.95 & 2.36 & 2.75 & 43.2 & 31.0 & 22.8 & 2.16 & 2.61 & 3.03 & 36.7 & 25.7 & 18.2 \\
\hline 3 & 1.82 & 2.23 & 2.59 & 47.4 & 34.5 & 25.8 & 2.02 & 2.45 & 2.84 & 41.0 & 29.2 & 21.3 \\
\hline
\end{tabular}

For a lower robot cost, a 100,000 $€$ return on investment will reduce to a payback of 3.21 and 2.71 years for the Netherlands and Israel, respectively. As expected, the return-oninvestment measures are sensitive to both the pepper price and the robot cost.

\section{Conclusions}

This paper presents a formulation for decisions related to the selective harvesting of individual fruit. The formulation serves as the basis for the operational decision of the production order and can assist farmers of selective crops in deciding how many fruit to harvest from each maturity class and the required number of harvesters (workers to hire for the harvesting season or equivalent performing robot). It takes into consideration four features, namely, time window constraints, resource limitations, yield perishability, and uncertainty. We suggest ways to deal with agricultural product uncertainty and adopted the formulation to different variations of the problem. The formulation was demonstrated here for a case study of sweet pepper harvesting. The case study presents the required cycle times for a robotic harvester and return-on-investment measures for different pepper and robot costs. The research formulation also enables the estimation of robot quality savings, a critical factor in a return on investment analysis and provides an economic analysis for different robot capabilities. The numerical examples analyzed the difference between types of worker and showed the potential added value of a robotic harvester, which can improve maturity classification and harvesting capabilities. This work focused on demonstrating use cases for farmers based on solutions obtained with personal computer-based systems. The aim was to show how our model can assist the individual farmer to decide on the production order. Specifically, we showed how this analysis can be used to decide on the number of workers and type of workers. Furthermore, the formulation results have proven the quality savings of a robotic harvester and reveal the importance of reducing its cycle times. A practical tool for the farmer can be 
developed based on this formulation and could be part of an IT package provided when renting a robotic system and/or part of a production management software.

The current operational model for selective harvesting can be developed further. The current formulation does not enable a combination of different types of workers/robots due to formulation complexity. This problem can be solved by developing a simulation model to simulate different combinations of workers and robots to determine the best combination. Despite this limitation, running the formulation separately for each available type of worker can contribute to the decision as to the best single type of worker to hire.

The current formulation does not take into consideration maturity classification mistakes of the robot and manual harvesters; thus, future research should consider adding such an analysis along with addressing inventory control aspects. Additional aspects of the robotic harvester that influence performance should also be considered, such as detection and grasping rates. These can influence the individual operational decision for a single fruit (whether to harvest or not) and not the overall production order (the number of workers to hire and peppers to harvest from each maturity level), which was the main goal of this paper. These future developments will be important once robotic harvesters will have become available and if human-robot collaborative harvesting is considered. The overall economic justification for robotic harvesting presented here indicates the need for further development of such harvesters. It demonstrates the importance of ensuring the high-quality maturity classification of such a robot and the reducing of its cycle time. The formulation of harvesting decisions related to the individual fruit is an important contribution to the field, providing a basic model in production and operations management of selective harvesting.

Author Contributions: Conceptualization: B.H., Y.E., Y.P.; Methodology: B.H., Y.E., Y.P.; Software: B.H.; Data analysis: B.H.; Interpretation of the data: B.H., Y.E., Y.P.; Writing-original draft preparation: B.H.; Writing—critical review and editing: B.H., Y.E., Y.P.; supervision: Y.E., Y.P.; project administration: Y.E.; funding acquisition: Y.E. All authors have read and agreed to the published version of the manuscript.

Funding: Partially funded by the European Commission (SWEEPER GA No. 66313) and by BenGurion University of the Negev through the Helmsley Charitable Trust, the Agricultural, Biological, and Cognitive Robotics Initiative, the Marcus Endowment Fund, and the Rabbi W. Gunther Plaut in Manufacturing Engineering.

Institutional Review Board Statement: Not applicable.

Informed Consent Statement: Informed consent was obtained from all subjects involved in the study.

Data Availability Statement: Not applicable.

Conflicts of Interest: The authors declare no conflict of interest.

\section{References}

1. Kusumastuti, R.D.; Van Donk, D.P.; Teunter, R. Crop-related harvesting and processing planning: A review. Int. J. Prod. Econ. 2016, 174, 76-92. [CrossRef]

2. Soto-Silva, W.E.; Nadal-Roig, E.; González-Araya, M.C.; Pla-Aragones, L.M. Operational research models applied to the fresh fruit supply chain. Eur. J. Oper. Res. 2016, 251, 345-355. [CrossRef]

3. Perlman, Y. Establishing a dual food supply chain for organic products in the presence of showrooming-A game theoretic analysis. J. Clean. Prod. 2021, 321, 128816. [CrossRef]

4. Ahumada, O.; Villalobos, J.R. Operational model for planning the harvest and distribution of perishable agricultural products. Int. J. Prod. Econ. 2011, 133, 677-687. [CrossRef]

5. Ahumada, O.; Villalobos, J.R. Application of planning models in the agri-food supply chain: A review. Eur. J. Oper. Res. 2009, 196, 1-20. [CrossRef]

6. Perlman, Y.; Ozinci, Y.; Westrich, S. Pricing decisions in a dual supply chain of organic and conventional agricultural products. Ann. Oper. Res. 2019, 1-16. [CrossRef]

7. Ozinci, Y.; Perlman, Y.; Westrich, S. Competition between organic and conventional products with different utilities and shelf lives. Int. J. Prod. Econ. 2017, 191, 74-84. [CrossRef] 
8. Grisso, R.D.; McCullough, D.; Cundiff, J.S.; Judd, J.D. Harvest schedule to fill storage for year-round delivery of grasses to biorefinery. Biomass Bioenergy 2013, 55, 331-338. [CrossRef]

9. Carpente, L.; Casas-Méndez, B.; Jácome, C.; Puerto, J. A model and two heuristic approaches for a forage harvester planning problem: A case study. TOP 2010, 18, 122-139. [CrossRef]

10. Starbird, S.A. Optimal loading sequences for fresh-apple storage facilities. J. Oper. Res. Soc. 1988, 39, 911-917. [CrossRef]

11. Higgins, A.J.; Muchow, R.C.; Rudd, A.V.; Ford, A.W. Optimising harvest date in sugar production: A case study for the Mossman mill region in Australia I. Development of operations research model and solution. Field Crops Res. 1998, 57, 153-162. [CrossRef]

12. Higgins, A.J.; Neville, D.W. Australian sugar mills optimize harvester rosters to improve production. Interfaces 2002, 32, 15-25. [CrossRef]

13. Kootstra, G.; Wang, X.; Blok, P.M.; Hemming, J.; van Henten, E. Selective Harvesting Robotics: Current Research, Trends, and Future Directions. Curr. Robot. Rep. 2021, 2, 95-104. [CrossRef]

14. Edan, Y.; Adamides, G.; Oberti, R. Agriculture automation. In Handbook of Automation; Springer: Cham, Switzerland, 2022.

15. De-An, Z.; Jidong, L.; Wei, J.; Ying, Z.; Yu, C. Design and control of an apple harvesting robot. Biosyst. Eng. 2011, 110, 112-122. [CrossRef]

16. Silwal, A.; Davidson, J.R.; Karkee, M.; Mo, C.; Zhang, Q.; Lewis, K. Design, integration, and field evaluation of a robotic apple harvester. J. Field Robot. 2017, 34, 1140-1159. [CrossRef]

17. Mehta, S.S.; Burks, T.F. Vision-based control of robotic manipulator for citrus harvesting. Comput. Electron. Agric. 2014, 102, 146-158. [CrossRef]

18. $\mathrm{Hu}, \mathrm{X} . ; \mathrm{Yu}, \mathrm{H} . ; \mathrm{Lv}, \mathrm{S}$; $\mathrm{Wu}$, J. Design and experiment of a new citrus harvesting robot. In Proceedings of the International Conference on Control Science and Electric Power Systems (CSEPS), Shangai, China, 28-30 May 2021; pp. 179-183. [CrossRef]

19. Feng, Q.; Zou, W.; Fan, P.; Zhang, C.; Wang, X. Design and test of robotic harvesting system for cherry tomato. Int. J. Agric. Biol. Eng. 2018, 11, 96-100. [CrossRef]

20. Arad, B.; Balendonck, J.; Barth, R.; Ben-Shahar, O.; Edan, Y.; Hellström, T.; Hemming, J.; Kurtser, P.; Ringdahl, O.; Tielen, T.; et al. Development of a sweet pepper harvesting robot. J. Field Robot. 2020, 37, 1027-1039. [CrossRef]

21. Edan, Y.; Rogozin, D.; Flash, T.; Miles, G.E. Robotic melon harvesting. IEEE Trans. Robot. Autom. 2000, 16, 831-835. [CrossRef]

22. Leu, A.; Razavi, M.; Langstadtler, L.; Ristic-Durrant, D.; Raffel, H.; Schenck, C.; Graser, A.; Kuhfuss, B. Robotic green asparagus selective harvesting. IEEE/ASME Trans. Mechatron. 2017, 22, 2401-2410. [CrossRef]

23. Bac, C.W.; van Henten, E.J.; Hemming, J.; Edan, Y. Harvesting robots for high-value crops: State-of-the-art review and challenges ahead. J. Field Robot. 2014, 31, 888-911. [CrossRef]

24. Harel, B.; Parmet, Y.; Edan, Y. Maturity classification of sweet peppers using image datasets acquired in different times. Comput. Ind. 2020, 121, 103274. [CrossRef]

25. Li, B.; Lecourt, J.; Bishop, G. Advances in non-destructive early assessment of fruit ripeness towards defining optimal time of harvest and yield prediction-A review. Plants 2018, 7, 3. [CrossRef]

26. Harel, B.; van Essen, R.; Parmet, Y.; Edan, Y.; van Essen, R.; Parmet, Y.; Edan, Y. Viewpoint Analysis for Maturity Classification of Sweet Peppers. Sensors 2020, 20, 3783. [CrossRef]

27. Kurtser, P.; Edan, Y. Statistical models for fruit detectability: Spatial and temporal analyses of sweet peppers. Biosyst. Eng. 2018, 171, 272-289. [CrossRef]

28. Džidiæ, A.; Halachmi, I.; Havranek, J.L. Prediction of Milking Robot Utilization Predvidanje iskoristenja robota za strojnu muznju. Agric. Conspec. Sci. 2001, 66, 137-143.

29. Halachmi, I.; Metz, J.H.M.; van't Land, A.; Halachmi, S.; Kleijnen, J.P.C. Case Study: Optimal facility allocation in a robotic milking barn. Trans. ASAE 2002, 45, 1539-1546. [CrossRef]

30. Halachmi, I.; Metz, J.H.M.; Maltz, E.; Dijkhuizen, A.A.; Speelman, L. Designing the optimal robotic milking barn, Part 1: Quantifying facility usage. J. Agric. Eng. Res. 2000, 76, 37-49. [CrossRef]

31. van Herck, L.; Kurtser, P.; Wittemans, L.; Edan, Y. Crop design for improved robotic harvesting: A case study of sweet pepper harvesting. Biosyst. Eng. 2020, 192, 294-308. [CrossRef]

32. Edan, Y.; Engel, B.A.; Miles, G.E. Intelligent control system simulation of an agricultural robot. J. Intell. Robot. Syst. 1993, 8 , 267-284. [CrossRef]

33. Johnson, L.K.; Bloom, J.D.; Dunning, R.D.; Gunter, C.C.; Boyette, M.D.; Creamer, N.G. Farmer harvest decisions and vegetable loss in primary production. Agric. Syst. 2019, 176, 102672. [CrossRef]

34. Temu, A.E.; Temu, A.A. High value agricultural products for smallholder markets in sub-saharan Africa: Trends, opportunities and research priorities. In Proceedings of the High Value Agricultural Products Workshop, Cali, Columbia, 3-5 October 2005; pp. 1-37.

35. Kapach, K.; Barnea, E.; Mairon, R.; Edan, Y.; Ben-Shahar, O. Computer vision for fruit harvesting robots-state of the art and challenges ahead. Int. J. Comput. Vis. Robot. 2012, 3, 4-34. [CrossRef]

36. Landahl, S.; Terry, L.A. Non-destructive discrimination of avocado fruit ripeness using laser Doppler vibrometry. Biosyst. Eng. 2020, 194, 251-260. [CrossRef]

37. Saranwong, S.; Sornsrivichai, J.; Kawano, S. Prediction of ripe-stage eating quality of mango fruit from its harvest quality measured nondestructively by near infrared spectroscopy. Postharvest Biol. Technol. 2004, 31, 137-145. [CrossRef]

38. Azarmdel, H.; Jahanbakhshi, A.; Mohtasebi, S.S.; Muñoz, A.R. Evaluation of image processing technique as an expert system in mulberry fruit grading based on ripeness level using artificial neural networks (ANNs) and support vector machine (SVM). Postharvest Biol. Technol. 2020, 166, 111201. [CrossRef] 
39. Ratprakhon, K.; Neubauer, W.; Riehn, K.; Fritsche, J.; Rohn, S. Developing an Automatic Color Determination Procedure for the Quality Assessment of Mangos (Mangifera indica) Using a CCD Camera and Color Standards. Foods 2020, 9, 1709. [CrossRef] [PubMed]

40. Lowenberg-DeBoer, J.; Huang, I.Y.; Grigoriadis, V.; Blackmore, S. Economics of robots and automation in field crop production. Precis. Agric. 2020, 21, 278-299. [CrossRef]

41. Allen, S.J.; Schuster, E.W. Controlling the risk for an agricultural harvest. Manuf. Serv. Oper. Manag. 2004, 6, 225-236. [CrossRef]

42. Zion, B.; Mann, M.; Levin, D.; Shilo, A.; Rubinstein, D.; Shmulevich, I. Harvest-order planning for a multiarm robotic harvester. Comput. Electron. Agric. 2014, 103, 75-81. [CrossRef]

43. Amaruchkul, K. Planning migrant labor for green sugarcane harvest: A stochastic logistics model with dynamic yield prediction. Comput. Ind. Eng. 2021, 154, 107016. [CrossRef]

44. Ferrer, J.C.; Mac Cawley, A.; Maturana, S.; Toloza, S.; Vera, J. An optimization approach for scheduling wine grape harvest operations. Int. J. Prod. Econ. 2008, 112, 985-999. [CrossRef]

45. Plà-Aragonés, L.M. Handbook of Operations Research in Agriculture and the Agri-Food Industry; Springer: Cham, Switzerland, 2015; ISBN 9781493924820.

46. Ampatzidis, Y.G.; Vougioukas, S.G.; Whiting, M.D.; Zhang, Q. Applying the machine repair model to improve efficiency of harvesting fruit. Biosyst. Eng. 2014, 120, 25-33. [CrossRef]

47. Arnaout, J.P.M.; Maatouk, M. Optimization of quality and operational costs through improved scheduling of harvest operations. Int. Trans. Oper. Res. 2010, 17, 595-605. [CrossRef]

48. Maatman, A.; Schweigman, C.; Ruijs, A.; Van Der Vlerk, M.H.; Maatman, A.; Schweigman, C.; Ruijs, A.; Van Der Vlerk, M.H. Modeling farmers' response to uncertain rainfall in Burkina Faso: A stochastic programming approach. Oper. Res. 2002, 50, 399-414. [CrossRef]

49. Annetts, J.E.; Audsley, E. Multiple objective linear programming for environmental farm planning. J. Oper. Res. Soc. 2002, 53, 933-943. [CrossRef]

50. Golenko-Ginzburg, D.; Sinuany-Stern, Z.; Kats, V. A multilevel decision-making system with multiple resources for controlling cotton harvesting. Int. J. Prod. Econ. 1996, 46-47, 55-63. [CrossRef]

51. Albornoz, V.M.; Araneda, L.C.; Ortega, R. Planning and scheduling of selective harvest with management zones delineation. Ann. Oper. Res. 2021. [CrossRef]

52. Maaike Wubs, A.; Ma, Y.T.; Heuvelink, E.; Hemerik, L.; Marcelis, L.F.M. Model selection for nondestructive quantification of fruit growth in pepper. J. Am. Soc. Hortic. Sci. 2012, 137, 71-79. [CrossRef]

53. Elkoby, Z.; Van Ooster, B.; Edan, Y. Simulation analysis of sweet pepper harvesting. In Proceedings of the IFIP International Conference on Advances in Production Management Systems (APMS), Ajaccio, France, 20-24 September 2014; pp. 441-448.

54. Melamed, Z. Analysis of Human-Robot Harvesting Operations in Sweet Pepper Greenhouses. Master's Thesis, Ben Gurion University of the Negev, Beersheba, Israel, 2016.

55. Nof, S.Y. Handbook of Industrial Robotics; John Wiley \& Sons, Ltd.: Hoboken, NJ, USA, 1999.

56. Sweeper Project Workpackages Overview. Available online: http://www.sweeper-robot.eu/workpackages (accessed on 1 December 2021). 